\title{
Robotic versus laparoscopic sleeve gastrectomy in the treatment of morbid obesity
}

\author{
ㄴ) Afag Aghayeva, ๑ İsmail Ahmet Bilgin \\ Department of General Surgery, Acıbadem Mehmet Ali Aydınlar University Faculty of Medicine, İstanbul, Turkey
}

\begin{abstract}
Introduction: Laparoscopic sleeve gastrectomy (LSG) has become the preferred procedure in the surgical management of morbid obesity. However, there are as yet few studies that include results of robotic sleeve gastrectomy (RSG). The purpose of this retrospective study was to compare the outcomes of RSG with those of the LSG technique.

Materials and Methods: The records of all patients who underwent LSG or RSG between December 2015 and April 2018 were retrieved retrospectively from the prospectively maintained registry of a single institution. The demographic details of the patients and the perioperative parameters and postoperative short-term outcomes were compared.

Results: A total of 41 patients were included (20 RSG patients vs. 21 LSG patients). There was no statistically significant difference in the demographic details, with the exception of age. The patients in the RSG group were younger than those in the LSG group $(p=0.038)$. The mean operating time was significantly lower in the LSG group ( $120 \pm 34.57$ minutes vs. $154 \pm 41.41$ minutes; $p=0.001)$. The mean estimated intraoperative blood loss was significantly lower in the RSG group $(13 \pm 14.18 \mathrm{~mL}$ vs. $28 \pm 16.30 \mathrm{~mL}, \mathrm{p}=0.003)$. There were no significant differences in the number of postoperative complications, reoperation rate, or the length of hospital stay between groups.
\end{abstract}

Conclusion: According to the results of this study, the robotic approach had comparable results to the laparoscopic approach in sleeve gastrectomy. Further prospective comparative studies are needed.

Keywords: Obesity; robotic; sleeve gastrectomy.

\section{Introduction}

Bariatric surgery has been shown to be more successful in the control of comorbidities resulting from obesity including hyperlipidemia, hypertension, and diabetes mellitus compared to a medical treatment. ${ }^{[1,2]}$ Laparoscopic sleeve gastrectomy (LSG) has increased its popularity in the last decade. ${ }^{[3,4]}$ As well as being an easy surgical procedure, it was also seen that this procedure had similar results with the laparoscopic gastric bypass (LGB) operation in the metabolic control.

The paradigm of surgery was changed by the laparoscopic equipment and the robotic technology further revolutionized it. Some technical limitations of the laparoscopic technology necessitated the development 
of the robotic platform. Unstable retraction, assistant-dependent visualization, and rigid instruments with limited range of motion were overcome by the robotic platform. Robotic sleeve gastrectomy (RSG) is an alternative approach to conventional LSG. Robotic assisted surgery was shown to lower the morbidity and mortality in Roux-en-Y gastric bypass that need more sutured anastomoses. ${ }^{[5]}$

The goal of this study was to present our technique of RSG and compare its short-term outcomes with conventional LSG.

\section{Materials and Methods}

Medical records of the patients who underwent RSG and LSG between December 2015 and April 2018 were reviewed retrospectively from a prospectively maintained archive. Data was obtained from research electronic data capture (REDCap) program. Institutional Review Board approval was obtained.

Demographics [body mass index (BMI), age, sex], perioperative parameters [operative time (OT), docking time, estimated blood loss (EBL), conversion rate, additional procedures] and postoperative short-term outcomes [postoperative complications, length of hospital stay (LOS)] were retrieved.

\section{Preoperative Evaluation}

The routine bariatric workup was performed by a surgeon, dietician, psychiatrist, endocrinologist and gastroenterologist. Preoperatively all patients underwent blood test, upper gastrointestinal endoscopy and hepatobiliary ultrasound. Preoperatively patients were fed with a high protein and low carbohydrate diet for 2 weeks to decrease the volume of liver. Thromboembolism prophylaxis was given to all patients preoperatively. Compression devices were put on the legs at the operation room.

\section{Surgical Technique}

Patients were positioned in reverse $15^{\circ}$ Trendelenburg position with legs separated and both arms extended. A urethral catheter and a nasogastric tube were introduced to all patients. For RSG, three $8 \mathrm{~mm}$ robotic trocars and one 12 $\mathrm{mm}$ laparoscopic trocar were used. A midline supra-umbilical incision was performed and $\mathrm{CO}_{2}$ insufflation was created with Veress needle. The camera port was introduced through this incision. Two $8 \mathrm{~mm}$ robotic trocars were placed from the left side of umbilicus and one $12 \mathrm{~mm}$ trocar was placed from the right side of umbilicus (Fig. 1a). Nathanson Hook Liver Retractor was placed through subxiphoid incision and liver was retracted superiorly. The robot was then docked and gastroesophageal junction was chosen for targeting. For transection of the stomach laparoscopic staplers $(60 \mathrm{~mm})$ were utilized in the laparoscopic approach. The bedside surgeon stood between patient's legs.

The gastrocolic ligament was opened and devascularization of the greater curve of the stomach was performed with a robotic vessel sealer (EndoWrist ${ }^{\circledR}$ Vessel Sealer) (Fig. 1b). Division of the gastrocolic ligament continued proximally up to the fundus and distally was completed at a level, 3-4 $\mathrm{cm}$ away from the pylorus.

Thanks to the ergonomic arms of the robotic platform, uppermost short gastric vessels were divided easily (Fig. 1c). This facility may theoretically ease in decreasing the risk of splenic injury or short gastric vessel bleeding. After total mobilization of the stomach, a 36-Fr bougie was advanced by the anesthesiologist and passed to the pylorus. Transection of the stomach started 3-4 $\mathrm{cm}$ proximal to the pylorus. The first two fires were done with the green cartridges and for the remaining yellow, black or white cartridges were used depending on the appearance of the stomach. With the aid of the ergonomics of the robotic arms, we experienced a better visualization of the retrogastric window and posterior part of the gastric fundus
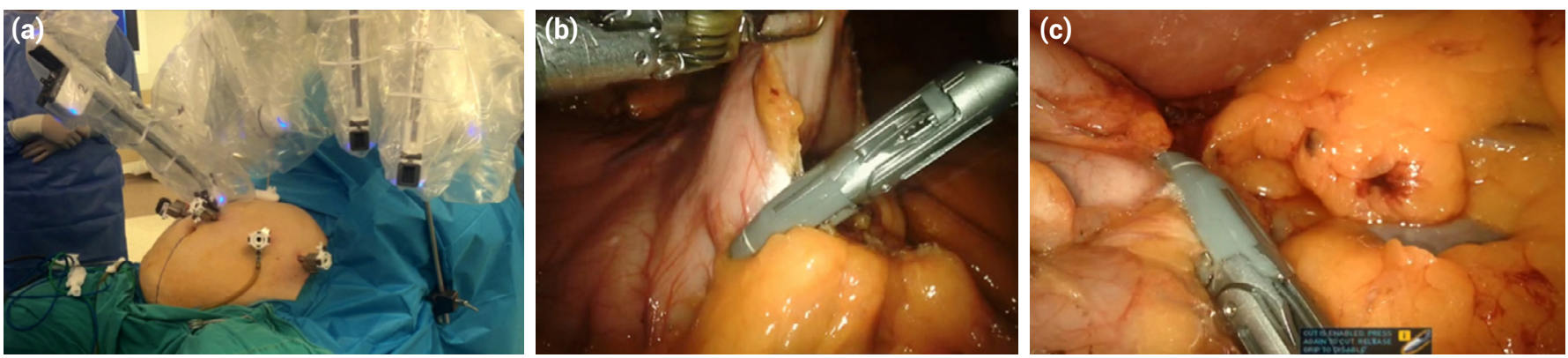

Figure 1. (a) Position of the trocars. (b) Devascularization of the greater curve of the stomach with robotic vessel sealer (EndoWrist $^{\circledR}$ Vessel Sealer). (c) Visualization of the retrogastric window. 
was excised ensuring with the final firing. We generally suture omentum and the staple line together to achieve both reinforcement of the staple line and to prevent twisting of the stomach. An air-leak test was performed to evaluate bleeding or any staple line leaks. Lastly, after the undocking of the robot, transected segment of the stomach was removed trough the $12 \mathrm{~mm}$ trocar side. A drain was placed in the stomach bed on surgeon's discretion.

\section{Postoperative Management}

At postoperative day one, patients underwent an upper gastrointestinal contrast-enhanced study. If there was no leak or stricture, a clear liquid diet was started and if present the drain was removed. At postoperative day two patients were discharged with the dietician's recommendations.

\section{Statistical Analysis}

Statistical analyses were performed with Epi Info Ver- sion 3.5.3. Comparisons between the robotic and laparoscopic groups were performed using Man-Whitney U test for quantitative variables, and Chi-square or Fishers's exact test for qualitative variables. When the parametric test conditions could not be achieved, the relationships between dependent variables of the study in both groups were analyzed by Spearman correlation test. $\mathrm{P}<0.05$ was considered statistically significant.

\section{Results}

A total of 41 patients underwent sleeve gastrectomy. Of these, 20 were RSG patients. Patient demographics were shown in Table 1. RSG group was younger than LSG group (mean; $33 \pm 11.39$ years vs. $40 \pm 10.52$ years, $p=0.038$ ). Perioperative findings were shown in Table 2. OT was shorter in LSG group (mean; $120 \pm 34.57 \mathrm{~min}$ vs. $154 \pm 41.41 \mathrm{~min}$, $\mathrm{p}=0.001$ ). The EBL was lower in RSG (mean; $13 \pm 14.18 \mathrm{~mL}$ vs. $28 \pm 16.30 \mathrm{~mL}, \mathrm{p}=0.003$ ). Mean docking time for RSG group was $4 \pm 1.41$ minutes (range, 3-10).

\section{Table 1. Patient demographics}

\begin{tabular}{lccr} 
& $\begin{array}{c}\text { Robotic sleeve } \\
\text { gastrectomy }(\mathbf{n = 2 0})\end{array}$ & $\begin{array}{c}\text { Laparoscopic sleeve } \\
\text { gastrectomy }(\mathbf{n = 2 1})\end{array}$ & $\mathbf{p}$ \\
\hline Age, year & $33 \pm 11.39$ & $40 \pm 10.52$ & 0.038 \\
Gender & 11 & 15 & 0.275 \\
Female & 9 & 6 & 0.979 \\
$\quad$ Male & $43.84 \pm 6.20$ & $45.36 \pm 11.11$ & \\
Body mass index $\left(\mathrm{kg} / \mathrm{m}^{2}\right)(\mathrm{mean} \pm \mathrm{SD})$ & & & \\
\hline SD: Standard deviation. & & & \\
\hline
\end{tabular}

Table 2. Peroperative and postoperative findings of the groups

\begin{tabular}{|c|c|c|c|}
\hline & RSG $(n=20)$ & LSG $(n=21)$ & $\mathbf{p}$ \\
\hline Operation time, $\min (\operatorname{mean} \pm S D)$ & $154 \pm 41.41$ & $120 \pm 34.57$ & 0.001 \\
\hline Estimated blood loss, $\mathrm{mL}$ (mean $\pm \mathrm{SD}$ ) & $13 \pm 14.18$ & $28 \pm 16.30$ & 0.003 \\
\hline Conversion to open & 0 & 0 & \\
\hline Reoperation & 1 & 0 & 0.488 \\
\hline Additional surgical procedures (cholecystectomy) & 3 & 7 & 0.172 \\
\hline Complications & & & 1.000 \\
\hline Bleeding & 1 & 1 & \\
\hline Leak & 0 & 1 & \\
\hline Stricture & 0 & 1 & \\
\hline Pneumatosis intestinalis & 1 & 0 & \\
\hline Hospital stay, day (mean $\pm S D)$ & $3 \pm 1.48$ & $3.38 \pm 1.77$ & 0.392 \\
\hline
\end{tabular}


Cholecystectomy was performed additionally in ten of the patients and this had no statistically significant effects on OT and EBL in both groups. Postoperative outcomes were shown in Table 2 . There were no statistically significant differences in the postoperative complication rates and LOS ( $p=1.000$ and $p=0.392$, respectively) between groups. In the RSG group, one patient developed pneumatosis intestinalis postoperatively and was managed conservatively. There was one staple line bleeding in the RSG group and was managed with laparoscopic staple line suturing. The reoperation rate between the groups was similar ( $\mathrm{p}=0.488)$. In the LSG group, one staple line bleeding was managed conservatively. Additionally, one patient in LSG group had staple line leak and was managed with endoscopic stent placement. The other patient with staple line stricture was managed with endoscopic stent. The mean LOS was $3 \pm 1.48$ days (range, $2-8$ days) in the RSG group and the reason for eight-day hospitalization was the development of pneumatosis intestinalis in one patient. The mean LOS was $3.4 \pm 1.77$ days (range, 2-9 days) in the LSG and nine-day hospitalization was due to a staple line stricture in one patient. There was no mortality during study period.

When Spearman coefficients of correlation were performed between groups, it was seen that there was no positive correlation in the RSG group, but there was positive correlation in the LSG group. In the LSG group, BMI was significantly positively correlated with the OT, EBL and LOS ( $R=0.520 ; p=0.016 ; R=0.466 ; p=0.033 ; R=0.657$; $\mathrm{p}=0.001$, respectively).

\section{Discussion}

According to the results of our study, the robotic approach for sleeve gastrectomy had comparable results related to the laparoscopic approach.

Snyder et al. ${ }^{[5]}$ reported that, robotic technology had advantages over the standard laparoscopy in complex and long procedures like robotic assisted Roux-en-Y gastric bypass. Besides, compared to LGB, LSG had some superiority including lower complication rates, shorter OT, and shorter LOS. ${ }^{[6,7]}$

In this study, the mean OT of RSG was $154 \pm 41.41 \mathrm{~min}$, and was in line with previously published studies with mean OT ranging from 106 to $157 \mathrm{~min} .{ }^{[8-11]}$

In the RSG group, three patients underwent synchronous cholecystectomy. The mean OT for these patients was
$167 \pm 15.28 \mathrm{~min}$ and this was not statistically significant compared to the rest of patients $(\mathrm{p}=0.164)$.

In the presented technique, we also oversaw (previously ligated gastrocolic ligament was stitched to the staple line) the staple line both (with an intent) to prevent twisting of the staple line and bleeding through it. The RSG technique was reported to be associated with longer OT compared to LSG ${ }^{[8,9,12]}$ Our results also agree with the formerly published reports regarding longer OT in RSG. Although statistically significant, the OT difference between RSG and LSG was 34 min, which was attributed to staple line sewing. Ayloo et al. ${ }^{[13]}$ observed similar results that oversewing staple line in the robotic arm increased the OT when compared to the laparoscopic arm that had not oversew the staple line.

In our study, the mean docking time was $4 \pm 1.41 \mathrm{~min}$. Our docking time was shorter than the published docking times of 6-19 min..$^{[10,12]}$ This could be due to our experienced robotic surgery team far beyond its learning curve. Our team performed more than 400 robotic procedures in the last 4 years.

In this study, while the EBL was significantly higher in the LSG group (RSG: $13 \pm 14.18 \mathrm{~mL}$; LSG: $28 \pm 16.30 \mathrm{~mL}$, $\mathrm{p}=0.003$ ) in general, the blood losses were acceptable in both groups. In this study, the mean age of the robotic arm was significantly younger than the laparoscopic arm ( $32 \pm 11.39$ years vs. $40 \pm 10.52$ years, $p=0.038$, respectively). This could be attributed to the increased interest of the younger patients to technological innovations, hence robotic technology.

One of the most feared complications of sleeve gastrectomy is staple line leakage, which was not seen in our robotic group but there was one leak in the laparoscopic group ( $\mathrm{p}=1.000)$. In a systemic review, the rate of leak was calculated as $2.4 \% \cdot{ }^{[14]}$ Diamantis and coworkers ${ }^{[15]}$ showed the leak rates as $1.8 \%$ and $0 \%$ for LSG and RSG, respectively. In other studies, there were no differences in the rates of leak and bleeding amounts between RSG and LSG approaches. ${ }^{[8,16]}$ In a meta-analysis, it was suggested that strengthening the staple line during LSG appeared to decrease staple line bleeding and overall complications. ${ }^{[17]}$ Reinforcing the staple line can be achieved much more easily with the enhanced dexterity of the robotic instruments. In our study, there was no significant difference in staple line leak, staple line hemorrhage and reoperation rate between the groups. 
One of the superiorities of the robotic technology in patients with $\mathrm{BMI} \geq 50 \mathrm{~kg} / \mathrm{m}^{2}$ could be its ergonomic advantage. Edelson et al. ${ }^{[18]}$ reported shorter OT in super-obese patients undergoing robotic gastric banding. Robotic platform overcomes manual difficulties faced by the surgeon in obese patients including dense abdominal wall and limited space due to increased abdominal fatty tissue. In our series, we had four patients with BMI $\geq 50$ and the OT of these patients ranged between 120 to $190 \mathrm{~min}$.

Higher costs are reported in RSG approach when compared to LSG approach. ${ }^{[9,19]}$ In the present study, we did not perform a cost analysis. Further decrease in the cost of the robotic procedures could be expected with the advent of other surgical robot companies in the near future.

Leaving large fundus can lead to poor postoperative weight loss. In order to avoid a leakage in the gastroesophageal junction, most surgeons prefer to stay away from this area and this leaves a large gastric fundus. A meticulous dissection of the left crus to mobilize the gastric fundus is the most critical part of the sleeve gastrectomy. Robotic platform can facilitate the mobilization and visualization of the fundus, especially in super-obese patients.

Limitations of our study were its retrospective design, patient selection bias and small sample size.

Other than cost, there are some other difficulties with the introduction of the robotic technology including learning curve, longer OT and availability of the robotic platform. When familiarizing new technology, it is essential to set oneself up for success, so we think that it is important to keep up with the technology.

\section{Disclosures}

Ethichs Committee Approval: The study was approved by the Local Ethics Committee.

Peer-review: Externally peer-reviewed.

Conflict of Interest: None declared.

\section{References}

1. Kashyap SR, Gatmaitan P, Brethauer S, Schauer P. Bariatric surgery for type 2 diabetes: weighing the impact for obese patients. Cleve Clin J Med 2010;77:468-76. [CrossRef]

2. Sjöström $L$, Lindroos $A K$, Peltonen $M$, Torgerson J, Bouchard C, Carlsson B, et al; Swedish Obese Subjects Study Scientific Group. Lifestyle, diabetes, and cardiovascular risk factors 10 years after bariatric surgery. N Engl J Med 2004;351:2683-93.

3. Sammour T, Hill AG, Singh P, Ranasinghe A, Babor R, Rahman
H. Laparoscopic sleeve gastrectomy as a single-stage bariatric procedure. Obes Surg 2010;20:271-5. [CrossRef]

4. Mognol P, Chosidow D, Marmuse JP. Laparoscopic sleeve gastrectomy (LSG): review of a new bariatric procedure and initial results. Surg Technol Int 2006;15:47-52. [CrossRef]

5. Snyder BE, Wilson T, Leong BY, Klein C, Wilson EB. Roboticassisted Roux-en-Y gastric bypass: minimizing morbidity and mortality. Obes Surg 2010;20:265-70. [CrossRef]

6. Gill RS, Birch DW, Shi X, Sharma AM, Karmali S. Sleeve gastrectomy and type 2 diabetes mellitus: a systematic review. Surg Obes Relat Dis 2010;6:707-13. [CrossRef]

7. Boza C, Gamboa C, Salinas J, Achurra P, Vega A, Pérez G. Laparoscopic Roux-en-Y gastric bypass versus laparoscopic sleeve gastrectomy: a case- control study and 3 years of follow-up. Surg Obes Relat Dis 2012;8:243-9. [CrossRef]

8. Romero RJ, Kosanovic R, Rabaza JR, Seetharamaiah R, Donkor C, Gallas M, et al. Robotic sleeve gastrectomy: experience of 134 cases and comparison with a systematic review of the laparoscopic approach. Obes Surg 2013;23:1743-52.

9. Elli E, Gonzalez-Heredia R, Sarvepalli S, Masrur M. Laparoscopic and robotic sleeve gastrectomy: short- and long-term results. Obes Surg 2015;25:967-74. [CrossRef]

10. Silverman CD, Ghusn MA. Early Australian experience in robotic sleeve gastrectomy: a single site series. ANZ J Surg 2017;87:385-9. [CrossRef]

11. Moon RC, Stephenson D, Royall NA, Teixeira AF, Jawad MA. Robot-Assisted Versus Laparoscopic Sleeve Gastrectomy: Learning Curve, Perioperative, and Short-Term Outcomes. Obes Surg 2016;26:2463-8. [CrossRef]

12. Vilallonga R, Fort JM, Caubet E, Gonzalez O, Armengol M. Robotic sleeve gastrectomy versus laparoscopic sleeve gastrectomy: a comparative study with 200 patients. Obes Surg 2013;23:1501-7. [CrossRef]

13. Ayloo S, Buchs NC, Addeo P, Bianco FM, Giulianotti PC. Robot-assited sleeve gastrectomy for super-morbidly obese patients. J Laparoendosc Adv Surg Tech A 2011;21:295-9.

14. Aurora AR, Khaitan L, Saber AA. Sleeve gastrectomy and the risk of leak: a systematic analysis of 4,888 patients. Surg Endosc 2012;26:1509-15. [CrossRef]

15. Diamantis T, Alexandrou A, Nikiteas N, Giannopoulos A, Papalambros $\mathrm{E}$. Initial experience with robotic sleeve gastrectomy for morbid obesity. Obes Surg 2011;21:1172-9. [CrossRef]

16. Magouliotis DE, Tasiopoulou VS, Sioka E, Zacharoulis D. Robotic versus Laparoscopic Sleeve Gastrectomy for Morbid Obesity: a Systematic Review and Meta-analysis. Obes Surg 2017;27:245-53. [CrossRef]

17. Choi YY, Bae J, Hur KY, Choi D, Kim YJ. Reinforcing the staple line during laparoscopic sleeve gastrectomy: does it have advantages? A meta-analysis. Obes Surg 2012;22:1206-13.

18. Edelson PK, Dumon KR, Sonnad SS, Shafi BM, Williams NN. Robotic vs. conventional laparoscopic gastric banding: a comparison of 407 cases. Surg Endosc 2011;25:1402-8.

19. Schraibman V, Macedo AL, Epstein MG, Soares MY, Maccapani $G$, Matos $D$, et al. Comparison of the morbidity, weight loss, and relative costs between robotic and laparoscopic sleeve gastrectomy for the treatment of obesity in Brazil. Obes Surg. 2014;24:1420-4. [CrossRef] 